\title{
A Developmental Evaluation of the Role of Faculty-based Student Support Coordinator
}

\author{
Rhona Sharpe \\ Oxford Brookes University, UK \\ Frances Deepwell \\ Oxford Brookes University, UK \\ Patsy Clarke \\ Oxford Brookes University, UK
}

\begin{abstract}
This paper evaluates the role of the faculty-based Student Support Coordinator (SSC) in a UK university. This paper asks how this new role is working in practice, what are the realities and tensions of the role, and what has been the impact to students? One of the challenges of implementing this new system was expected to be ensuring that all those involved understand their roles and help students to make use of them appropriately. Data were collected both from the student support coordinators themselves and staff they worked alongside via interview and attendance at meetings. Data were also collected from students via interviews and surveys. The feedback from students showed an increasing awareness of the service offered by SSCs over time and a high level of satisfaction. This developmental evaluation has clarified and protected the role of the SSCs and uncovered aspects of their role that had not been foreseen.
\end{abstract}

Keywords: student support; developmental evaluation; roles; boundaries; accessibility; visibility.

\section{Introduction}

Recent years have seen quite a shift in the recognition of the need for effective student support systems and the affective dimension of the student experience. We have moved 
from a position where universities were considered 'emotion free zones' where emotions were 'inappropriate territory' (Mortiboys, 2002, p.7) to one where emotions, and particularly feelings of 'belonging', are understood to be key factors in student retention and achievement, with an emphasis on supporting students through induction, encouraging peer support and friendships, and personal tutoring (Thomas, 2012). For example, in a study of first year dental students, Burk and Bender (2005) found that problems perceived as serious by students are of an emotional nature relating to academic performance, and students use both formal and informal peer support systems.

The growing evidence of the links between student support and retention and attainment (Yorke, 2004; Yorke and Thomas, 2003) has led to an increase in the provision of student support services and the reconsideration of the role of the personal tutor. Support services are often located centrally and it is assumed that students will access the appropriate service as and when they need it. However, we know that even where there is high need for support, some students don't seek support at all (Malik, 2000) or seek but do not find it (Thomas, 2012).

There have been attempts to relate satisfaction to the types/approaches of support that are offered, and with student demographic and personality characteristics (Mottarella et al., 2004). Overall they show that what students value is 'a good relationship' with their adviser, however that might be expressed (Malik, 2000; Stephen et al., 2008). This evidence is strikingly similar to that from psychotherapy where the nature of relationship between therapist and client contributes more to satisfaction than the therapeutic approach adopted by the therapist (Beutler et al., 1994). Indeed McGahey and Szumko (2006) made explicit links between psychotherapy and academic tutoring, using the principles of person-centred counselling to identify key factors in academic tutoring relationships. It is also clear that regular and frequent meetings are important in establishing such a relationship (Malik, 2000).

There is a need then for universities to take stock of the arrangements for support within their institutions, in particular to ensure that services are accessible to and used appropriately by students. This is a highly complex situation, with many players involved and a constantly evolving institutional and political backdrop to student learning support and academic development. Consequently, it seemed fitting to embark on a developmental evaluation (Patton, 2011) since this provided us with a cross-institutional 
approach that would enable what is learned from the evaluation to be incorporated into decision-making in a timely manner.

Developmental evaluation 'tracks and attempts to make sense of what emerges under conditions of complexity, documenting and interpreting the dynamics, interactions and interdependencies that occur as innovations unfold' (Patton, 2011, p.7). Developmental evaluation brings the evaluators into close partnership with decision-makers. As with many evaluation studies, we draw on a range of enquiry methods, as indicated in the methods section of this paper, however the developmental approach keeps us mindful of what Patton (2008) terms 'process use', that is, a sensitivity to how engagement in the evaluation is affecting those involved and their relationships within the organisation. In some respects, developmental evaluation is akin to action research, with its emphasis on cycles of engagement, critical reflection and action, or development. In contrast to much action research, however, developmental evaluation provides a clear distinction between an enquiry role and a co-ordination or decision-making role, and in our case, rather than being problem-focused, the initiative we are evaluating is a programme of student support with a set of outcomes that has largely shaped the inquiry (Patton, 2011, p.281).

\section{Context}

Oxford Brookes University is a modern UK university of 18,000 students with a high reputation for teaching quality. The institution is spread over four campuses, and most faculties have students on at least two different campuses. In 2009, the university commissioned a review of undergraduate student support conducted by an external consultant (Laycock, 2008), with the key recommendations that:

The university adopts a consistent, whole-institutional, strategic student support framework which clearly signals its commitment to a 'supportive learning community'.

The university re-conceives personal tutoring and moves from a reactive, deficit model to a more proactive, structured approach and associated student support 
Two roles were created in line with these recommendations and thus started the transition from a model of support based around the personal tutor as the primary source of local student support, to a model based around Student Support Coordinators (SSCs) and Academic Advisers. The notion of the SSC was in part based on a system which was already well established in one academic faculty. Each faculty began implementing their own variation on this model. In essence, the role of the SSC is to provide a one-stop shop for students in a convenient location for each faculty, handling enquiries on a broad range of issues, answering them where they can, offering support and acting as a referral service. The SSCS are dedicated staff (often recent graduates) whose role is providing accessible and timely advice to students within their faculty. This should free up Academic Advisers (who are academics from the discipline) to be the students' main point of contact for academic guidance throughout their study. The role of the Academic Adviser is to monitor, promote and facilitate the academic development and progress of students assigned to them.

This model of support is interesting to learning developers in a number of ways. First, it moves away from a deficiency model of student support towards a system which offers students proactive support, structured into their programme of study through their connection with a named Academic Adviser, and through the availability of locally based SSCs. Second, it moves learning development and support closer to the students' study of the discipline by locating it within the academic space with which students associate themselves. This two-part support model complements a central student support service, including an academic skills centre, and is supplementary to other learning development that is fully embedded in the curriculum. This builds on earlier work showing the benefits of integrating learning development into the curriculum (Hill et al., 2010; Hill et al., 2011).

Whilst the location of student support within faculties is not new, the present study provides an insight into how students experience advice and guidance in such a model, and in particular explores their decision-making process when seeking such support. Of particular interest is the creation of short vignettes to tell student stories, which allow the complex and on-going nature of support issues to show through, and to provide meaningful narrative to prompt discussion (Hall and Peat, 2012).

Where this new system works, the benefits to students should be an easily accessible and responsive source of faculty-based advice and information (through the SSCs) and a 
longer-term relationship with a member of academic staff for academic advice and guidance (through the Academic Advisers). The current evaluation study asks.

1. How are the SSCs' roles working in practice?

2. How accessible are sources of faculty based support?

3. What is the impact of the new model of student support for students?

This study was commissioned by the main teaching and learning committee of the university, and designed, undertaken and disseminated in ways that were intended to have the most impact. The work needed to be participative, highly visible, and presented in a way that engages the reader with the evidence. This paper focuses on the role of SSCS. A similar examination of the roles of Academic Advisers, who are subject-based academic staff, will be reported in a subsequent paper.

\section{Method}

This paper draws on data from the larger evaluation, which took place over two years. The project had full approval from the university ethics committee. In line with the developmental approach of the evaluation, SSCs have been engaged in all stages of the research project, including commenting on and piloting the surveys, and sharing their perspectives on student support. The developmental evaluation approach also meant that data were collected in ways which would produce outputs which we could use to engage our audience of university decision-makers in order to improve the impact of the study.

\section{Online survey}

The survey had three sections:

- About you: age, gender, Faculty, UK residency, first language, level of study.

- Where do you prefer to go for advice and information?

- About faculty based support received from SSCs or Academic Advisers in terms of ease of accessibility and satisfaction.

In 2010, the survey was made available via Survey Monkey for three weeks in Semester Two. Invitations to complete the survey were distributed by e-mail to undergraduate 
students by their senior academics. Prizes of high street shopping vouchers were offered as an incentive. The survey was accessed by 253 students and completed by 228 .

In 2011, the survey was again made available via Survey Monkey for three weeks in Semester One. In an attempt to increase the number of completed surveys, in addition to distribution by senior academics, the survey was also advertised on the Message of the Day which students see when logging in to university computers, and on the Student's Union Facebook site. Prizes of high street shopping vouchers were offered as an incentive. As shown in Table 1, in 2011, the survey was attempted by 309 students with 250 usable submissions.

Table 1. Demographic characteristics of survey respondents.

\begin{tabular}{llrc}
\hline & & \multicolumn{2}{c}{ Time of data collection } \\
& & May & Nov \\
2010 & 2011 \\
& & $(\mathrm{n}=228)$ & $(\mathrm{n}=250)$ \\
\hline Level of study & Undergraduate & 0 & 214 \\
& Postgraduate & & 36 \\
Age & & 139 & 116 \\
& $18-20$ & 62 & 94 \\
& $21-30$ & 27 & 40 \\
Gender & $31+$ & & \\
& Female & 175 & 188 \\
& Male & 53 & 62 \\
& & & \\
\hline
\end{tabular}

\section{Comments Cards}

In 2011, Comments Cards were created in paper and online. SSCs gave these cards to students that they saw during Weeks 8-9 of Semester One 2011/12 and added the link to the online form to their e-mail footers. There were 187 Comments Cards received, around half of which were from one faculty. 


\section{Student interviews}

Students who completed the online surveys were asked to indicate if they were willing to be interviewed. Ten interviews were conducted during May-June 2010 and a further ten in January-February 2012. Interviews were audio recorded and in 2012 were also transcribed. Students who attended the interviews were given a $£ 5$ meal voucher. The interviews and their transcripts were used to create short vignettes, which capture the support needs and experience of gaining support of each student during their time at Brookes. The full text of each anonymised story was agreed by each student prior to publication.

\section{Staff interviews}

Semi-structured interviews were conducted with SSCs individually or in groups in May $2010(n=6)$ and again in February $2012(n=5)$. Interviews were audio recorded. Interviews were held in SSCs' usual office space and photographs were taken of the spaces in which SSCs work. The interviews were also an opportunity to collect documentation.

Interviews were conducted with Academic Advisers ( $n=18$ ): five in June 2010, four in November 2010 and nine in March 2012. All faculties were represented in the interviews. The interviews lasted around 45 minutes and were audio recorded.

The evaluation team attended several SSC Network Meetings to discuss the purposes and findings of the evaluation, and hear collectively from SSCs about their experiences. Attendance at these meetings, chaired by a senior manager, facilitated short-term actions, such as training or clarification of job role, to be progressed efficiently.

\section{Findings and discussion}

The intention was that SSCS would provide a one-stop shop in each faculty for students, handling enquiries on a broad range of issues, answering them where they can, offering support, and acting as a referral service. One of the challenges of implementing this new system was expected to be ensuring that all those involved understand their roles and help students to make use of them appropriately. The benefits to students should be an accessible and responsive source of faculty-based advice and information. 


\section{How are the SSCs' roles operating in practice?}

In year 1, SSCs were found to be taking on a very wide range of other roles in addition to dealing with individual queries. Placing SSCs within faculties, rather than centrally, had led to SSCs taking on additional duties from within their faculties. We noted at the time that the challenge for SSCs was going to be to decide which roles contribute to their ability to perform their individual support and referral service. By year 2, a generic job description had been created for all SSCS and at interview SSCS were clear about the boundaries of their role and familiar with the job description. SSCs gave similar descriptions of their role at interview and were able to quickly explain it, for example:

Provide advice, guidance, support and information. We signpost to other services and provide encouragement and motivation. (SSC interview 2)

We are the first port of call for students who have questions about anything really about their programme, personal, external things to uni. (SSC interview 4).

A full breakdown of the descriptions SSCs gave of their roles is given in Table 2. These are not presented in any particular order. The SSCs noted the broad scope of their role: 'Whatever's needed - whenever it's needed' or 'the faculty's answer to Google'.

Table 2. Summary of activities reported by Student Support Coordinators as part of their role.

\begin{tabular}{|l|l|}
\hline All SSCs were undertaking the following core duties: & $\begin{array}{l}\text { In addition, some SSCs had } \\
\text { responsibility for: }\end{array}$ \\
\hline $\begin{array}{l}\text { Being available for visits, drop-ins, being the first port } \\
\text { of call for queries, practical advice, or pastoral }\end{array}$ & $\begin{array}{l}\text { Student Forums (regular } \\
\text { student feedback sessions): } \\
\text { support. }\end{array}$ \\
$\begin{array}{l}\text { Making assessments of students' needs and referrals } \\
\text { as appropriate, e.g. to subject academics, academic } \\
\text { management offices, counselling, disability, medical } \\
\text { centre, student skills advisors, student union advisory } \\
\text { services. }\end{array}$ & $\begin{array}{l}\text { Fattending. } \\
\text { Faculty based academic and } \\
\text { cultural orientation programme. } \\
\text { Careers events and weekly e- }\end{array}$ \\
\hline
\end{tabular}




\begin{tabular}{|c|c|}
\hline $\begin{array}{l}\text { Complex query solving. SSCs often take on problems } \\
\text { that students have been unable to solve through visits } \\
\text { to other services, and see them through to resolution. } \\
\text { Providing timely advice for groups of students e.g. } \\
\text { running scheduled advice sessions for particular } \\
\text { groups of students, sometimes negotiated through } \\
\text { programme teams. } \\
\text { Activities to increase their visibility e.g. presentations } \\
\text { to students on visit days and during induction, and to } \\
\text { staff in staff development week, making up posters, } \\
\text { leaflets, maintaining notice boards. } \\
\text { Providing information to students in accessible ways } \\
\text { e.g. leaflets, newsletters, regular e-mail updates. } \\
\text { Attending meetings: faculty learning and teaching } \\
\text { committee, admissions, subject committees, exam } \\
\text { committees and programme meetings. } \\
\text { Building links within and outside the university e.g. } \\
\text { services which support careers, international students } \\
\text { services, mental health issues. }\end{array}$ & $\begin{array}{l}\text { mail updates. } \\
\text { Recruiting and supporting open } \\
\text { day guiders. } \\
\text { Coordinating arrangements for } \\
\text { student induction. } \\
\text { Tier } 4 \text { attendance monitoring. }\end{array}$ \\
\hline
\end{tabular}

Hill et al. (2010, p.5) reflect on the location of support services, noting that those based in academic departments value 'the inclusiveness and collaboration that is engendered'. We found a number of examples of this. Some SSCs found themselves part of the departmental community to such an extent that they were advising and supporting staff as well as students. In some cases this may be related to student support, but in others it was direct support for staff:

Staff come in and tell us about their problems, and their students. We get both sides. We get the staff and the student perspective. We mediate. (SSC interview 1)

Being included in the community also allows SSCs to take active steps to make contact with and offer support to students who are hard to reach or may be disengaging, such as those who are failing modules, not-attending, or not submitted assessed work. Where Hill et al. (2010) promote the use of an individual learning profile, SSCs were using existing 
data in the student records system and contacting those students with errors displayed on their record pages, or e-mailing all students who have received notification of failure letters from the exams office. In one faculty, module leaders have started to monitor attendance at seminars. They send the names of students who have missed more than two seminars to the year tutors, who pass them on to the SSC. The SSCs e-mail these students to offer support. One SSC describes this as a lot of work but worth it for the students it does pick up.

Being located closer to the departments also gives the potential for support and learning development to be targeted. SSCs were asked how they operated within the context of their faculty. All were able to talk knowledgeably about what mattered to the students they were responsible for, whether that was Law students' concern with passing professional modules and achieving a good final classification, or healthcare students' concern with staff assessing their competence to practice. Some SSCs also gave examples of adapting their work for students in their discipline. For example, in Built Environment, the SSCs were deliberately using a lot of graphics in their materials to appeal to their students. In another example, SSCs in healthcare adapted their introductory presentations to new students to the programmes that they were going to see, e.g. students taking the adult nursing programme are mainly school leavers away from home for the first time, so the presentation focuses on how they can help students sort out practical problems as well as dealing with homesickness and feeling lonely. As one SSC explained:

Part of working with people is understanding what is going on for them, and having a part in their department's life. (SSC Interview 3)

There were challenges to the role operating effectively in practice. Firefighting was a recurrent issue raised by SSCS who reported that problems were caused by systems (notably student records and mitigating circumstances systems) and the SSC was needed to explain, interpret and fix problems caused by these systems. For the SSCs, this means that they don't have the time to do as much proactive work as they would like. They are frequently torn between wanting to undertake proactive support work and wanting to be available to students who may be in crisis. One SSC, who thought the proportion of their time they spent 'firefighting' was about $40 \%$, described this as: 
Dealing with problems that shouldn't be problems, so for instance students will go to academic management or exams and will receive a really bad response from these departments in relation to their query. They'll come to us and then we'll have to call up those departments and liaise with them, and I spend a lot of my day doing that, trying to get answers to solve whatever the issue is. (SSC Interview 1 )

Another challenge is defining the boundaries of the role. Previous studies have emphasised the affective dimensions of being a student and the interaction between emotion and academic performance (Beard et al., 2007; Burk and Bender, 2005). SSCs are on the sharp end of this and talked about the boundaries of their role being between personal support and counselling. SSCs were clear to state their position, that they were not counsellors, for example:

We are careful not to unpack anything in too much detail because we are not here as counsellors, more as a signposting and advisory service. (SSC Interview 1)

However, SSCs also recognised, as McGahey and Szumko (2006, p.1) have done, that 'it is impossible to separate a person from their feelings'. Some SSCs are seeing counselling as a potential career development route and some already use counselling skills in other roles outside work. All were appreciative of being offered a 'counselling for noncounsellors course', and most have created physical spaces which are designed to be warm, welcoming, safe, and private. Consequently, although SSCs are clear to answer the question about their boundaries with care, there may be a need to make this boundary between pastoral support and counselling clearer to students.

The SSCs at interview were also clear to distinguish their roles from other sources of support within the faculties. The model of faculty-based student support distinguishes clearly between the roles of SSC and Academic Adviser. However, distinct roles do not imply separate ones. Indeed the SSCs thought the SSCs and Academic Adviser roles worked best when they communicated well, giving an example of collaborating when a student is in trouble:

We'll phone them and they'll phone us to say 'have you seen so and so'? I've seen them and this is what's happening so you can keep your eye on them. (SSC Interview 4) 
The vignette created from Ben's interview describes how the system works, when it is working as intended:

Towards the end of his first year Ben consulted his Academic Adviser when he had become stressed from an overload of academic work. Ben knew to consult the Academic Adviser as there were compulsory group or individual sessions to introduce the Academic Adviser right from the start. He found it useful to have someone to bounce ideas off and help form a plan to carry him through the next two years, continuing with a broad-based set of subjects while reducing the number of modules. As Ben needed help to set up the planned modules, he was then referred to a Student Support Coordinator who 'knew her stuff' and was able to sort that out for him within a half hour.

\section{How accessible are SSCs as a source of faculty based support?}

Hill et al. (2010) recognise the importance of visibility and accessibility to devolved support services and our interviews with SSCS also highlighted efforts the SSCs have made to improve their visibility. For example, in Health and Life Sciences, the SSCs have promoted a specific visual identity, associated with a bright yellow colour, which they use on all their publications from their T-shirts on induction days to flyers and posters around the site. SSCs engage students from pre-arrival with a flyer in pre-arrival packs, going into every class in orientation week and again 3-5 weeks later as part of an extended student induction.

Students who responded to the survey were asked if they knew where to find the SSC in their faculty. In May 2010, towards the end of the first year of the new system, 32.0\% of undergraduate survey respondents knew where to find their SSC. By the time of the second survey in November 2011, awareness of SSCs had increased to $50.5 \%$ of students, an $18.5 \%$ improvement. Such an improvement is welcomed and reflects the efforts SSCs have made to improve their visibility. In the open comments, survey respondents reported that they had found out about their faculty SSCs from a range of information sources or events. Mentioned frequently were the presentations and introductions by SSCs during orientation weeks, attendance by SSCs at student-staff meetings, and regular e-mails. 
In the interviews with SSCs, it was noticeable that in year 1 they were focusing on establishing their visibility, whereas in year 2 they were also concerned with improving access to their services. The most obvious improvement to access has been the relocation of many SSCs to more visible locations within their faculties. Other things that SSCs are doing to make their services more accessible include a joint faculty-wide e-mail inbox, consistent and established drop-in hours, and appointments bookable by e-mail.

The Comments Cards given to students who had seen an SSC asked 'How easy was it to meet with your Student Support Coordinator?' Table 3 shows that for students who had been to see their SSC, they considered it very easy to meet with them.

Table 3. Comments Cards.

How easy did you find it to meet with the SSC?

\begin{tabular}{cllll}
\hline Very & Quite & Not very & $\begin{array}{l}\text { Not } \\
\text { at all }\end{array}$ & Total \\
\hline $164(87.7 \%)$ & $19(10.2 \%)$ & $3(1.6 \%)$ & $1(0.5 \%)$ & 187 \\
\hline
\end{tabular}

Thinking of the issue which took you to see your Student Support Coordinator, were you able to resolve it during your meeting?

\begin{tabular}{lllll}
\hline Completely & Mostly & A little & $\begin{array}{l}\text { Not } \\
\text { at all }\end{array}$ & Total \\
\hline $109(58.3 \%)$ & $63(33.7 \%)$ & $12(6.4 \%)$ & $3(1.6 \%)$ & 187 \\
\hline
\end{tabular}

If your Student Support Coordinator directed or referred you to another source of support, how useful was this recommendation?

\begin{tabular}{lllll}
\hline Very & Quite & Not very & $\begin{array}{l}\text { Not } \\
\text { at all }\end{array}$ & Total \\
\hline $105(71.9 \%)$ & $33(22.6 \%)$ & $6(4.1 \%)$ & $2(1.4 \%)$ & 146 \\
\hline
\end{tabular}




\section{What do students say about the support coordinators?}

The evaluation of students' experiences drew on evidence from comments cards, the online survey and in-depth interviews with students. It is worth noting that all these data collection methods involved students self-selecting to take part. In evaluating the value of the SSCs role, we were particularly interested in their ability to refer and/or resolve issues to avoid students being passed around different services. Students were also asked about the usefulness of information received and the impact that meeting with an SSC had for them.

The Comments Cards asked about the extent to which the SSC was able to resolve the issue presented and the quality of any referral. Table 3 shows that more than half of the issues are being resolved completely and, where SSCs cannot resolve the issue, they offer high quality referrals. The following example is taken from the open comments provided by a student in the online survey:

The problems I went to see my student support coordinator couldn't be fixed on the spot, but she helped me think about what I had to do to sort them out and she pointed me in the right direction and gave me very helpful advice.

In 2010, of the 228 survey respondents, 37 (16.2\%) had been to see a SSC. Table 4 shows that the SSCs were rated very highly by this group with 93\% of students finding the advice and information received quite or very useful. By 2011, with the increase of awareness of students concerning their faculty SSCs, a total of 67 (31.3\%) of the undergraduate survey respondents had been to see their SSC. Slightly more than this, a total of 80 students, answered the questions about the usefulness of information that they had received from SSCS, presumably referring to contact with SSCs other than visits. Of these, 76 (95\%) responded that they found the advice from SSC(s) 'very useful' or 'quite useful'.

Table 4. How useful is the advice and information from SSCs?

\begin{tabular}{lccccl}
\hline & $\mathbf{n}$ & \multicolumn{1}{l}{ Very } & Quite & Not very & Not at all \\
\hline $\mathbf{2 0 1 0}$ survey & $37 / 228$ & $24(64.9 \%)$ & $9(24.3 \%)$ & $4(10.8 \%)$ & $0(0 \%)$ \\
\hline $\mathbf{2 0 1 1}$ survey & $80 / 214$ & $47(58.8 \%)$ & $29(36.3 \%)$ & $3(3.7 \%)$ & $1(1.2 \%)$ \\
\hline $\mathbf{2 0 1 1}$ Comments cards & 187 & $161(86.1 \%)$ & $25(13.4 \%)$ & $1(0.5 \%)$ & 0 \\
\hline
\end{tabular}


The open comments left on the Comments Cards are overwhelmingly positive, of which the following is typical:

The Student Support Coordinator really does offer great advice and help to the students. I had a lot of problems, and really didn't know what to do with them, but after seeing the Student Support Coordinator, things became so much clearer. To be quite frank, if this service was not available, I'm not sure I would have got certain issues sorted out, at all! They are very friendly and caring, and will always have time for you. I can now relax more, and concentrate on my studies.

Student Support Coordinator service is one of the best services of the university. Any time I come, I get the answers to all my questions, I am really pleased with the service.

The open comments show that students particularly value that SSC are:

- Well informed, offer good advice.

- Prompt and timely responses to e-mails.

- Follows up when says is going to.

- Listen well.

- Friendly.

- Approachable.

- Refer on appropriately.

- Have good dialogue with students.

- Always available, never too busy.

- Making proactive contact.

- Managing student issues sensitively.

In some cases the students responding to the survey left no doubt as to the effect of their access to an SSC:

I probably would have left university a long time ago if it wasn't for my SSC. 
This role is so important to students. We had no one before student support coordinators.

However, it is the stories from individual students gained through interview which demonstrate the complexity of support needs, the many interactions students have with a number of different support services, and the long-term impact to them of finding the support they need. These highly engaging outputs prompted debate within the institution and gave life to the project reports. Table 5 gives a flavour of these stories.

Table 5. Summary of some of the vignettes created through interviews with students.

Janice is a mature age student whose most recent motivation for seeking help was as she felt she was not doing as well as she could in her essays. Janice had a good chat with one of the Student Support Coordinators and also discussed a personal matter concerning her responsibilities.

Lizbeth is a second year International student who began her first semester one January when other students were entering their second semester.

Marion. In her third year of study, feedback from lecturers that referred to her work's 'sloppiness', 'carelessness' and 'poor spelling' provoked Marion's decision to formally register her dyslexia.

Naomi is an international student who arrived in Oxford with others from her home region to study at Brookes, without any pre-arrival information.

Sheera, an international student in her second year of study, has developed good relationships with both her Field Chair and her Academic Adviser.

Sonya sought advice from a lecturer on arrival. Having always received good advice and support over the intervening three years, Sonya has continued to make her senior lecturer her first port of call. 
Wayne realised within two weeks of arriving at university that the subject he had registered for did not meet his expectations.

Conrad is a mature age student who is the first in the family to study at university. He applied to Brookes after he was made redundant from his job. Conrad has sought support in choosing and registering for modules, and from the Careers centre in supporting his change of career direction.

Julia is a third year student from the EU, who discusses her support needs with regard to accommodation, employment and use of academic English.

Penny is a mature student in her first year, who has been supported by the Mature Student Society. She describes her frustrations with communicating poor learning experiences to staff in her School.

Note: These stories make use of pseudonyms. Each student has confirmed the contents of their story for use in the project.

\section{What use has been made of this developmental evaluation?}

The Oxford Brookes Strategy for Enhancing the Student Experience (Oxford Brookes University, 2010) includes a commitment to evidence based policy development, stating that:

Making use of our internationally recognised in-house expertise in educational development, we commit to routinely carrying out impact assessment, review and revision of all significant academic development initiatives and of measures taken forward in the SESE and the consequent strategy maps. Impact assessments will be sustained and iterative. They will assess the process as well as the end product of developments. [SESE 4.4.3]

The evaluation of faculty based student support was one of the first academic development projects to be commissioned by the main university teaching and learning committee under this new commitment. It demonstrates an institutional approach to developmental evaluations that are iterative and ongoing, which inform our community's 
activities, and are a tool for positive change. Coming back to 'process use' as identified at the start of this paper, we can identify that the SSCs and faculty colleagues have become far more confident in the purpose and function of the role and in navigating the boundary areas with other support professionals, for example, Academic Advisers, counselling, careers or study skills specialists.

The project and its findings have also been used to inform the following institutional decisions:

- The integration of SSCs into faculty processes, including giving them a place on each faculty's learning and teaching committee.

- The creation of a generic job description for SSCs, which clarified and protected the important parts of their role.

- The move to more visible offices within faculties for a number of SSCs.

- The creation of a working group to further define the role of the Academic Adviser and how it interacts with the SSCS.

The project confirmed the decision to place SSCs within faculties, finding evidence that being based locally is considered to be important by both SSCs and students. The advantages are that SSCs can be more visible to students and other staff, aiding communications and referrals between SSCs and academic staff. SSCs are now formally members of each Faculty's learning and teaching committee and contribute actively based on their interactions with a wide diversity of students. Importantly, it was found that faculty based SSCs can understand and be part of the students' experiences, enabling them to offer useful advice and information and, where necessary, referrals. From within the faculties they can also initiate and maintain the regular contacts with students, thereby making real our notion of proactive support. In an earlier article in this journal, Bishop et al. (2009, p.1) typify their role as learning developers through metaphors, including 'Mrs Mop, Mechanic and/or Miracle Worker'. It may help to understand more deeply the role of faculty-based SSCs in our study where we found metaphors emerging such as 'firefighters', 'sign-posts' and 'first port-of-call'.

There is still work to be done, and the evaluation work continues, but it is now embedded in annual processes and institutional networks. SSCS and students still need to find the boundaries around dealing with the emotional aspects of being a student. There is 
potential to use the SSCs to collect data which could be a powerful source of information on how best to support students and to assess the impact of different types of interventions. There is still potential for the SSCs' role to have more impact if they were able to contain the firefighting aspects of the role to devote more time to what we have found to be highly valued, and effective activities such as proactive and preventative support work in contacting students at risk of disengaging.

\section{References}

Beard, C., Clegg, S. and Smith, K. (2007) 'Acknowledging the affective in higher education', British Education Research Journal, 33(2), pp. 235-252.

Beutller, L.E., Machado, P.P. and Neufeldt, S.A. (1994) 'Therapist variables', in Bergin, A.E. and Garfield, S.L. (eds.) Handbook of psychotherapy and behavioural change. New York: Wiley, pp. 229-69.

Bishop, C., Bowmaker, C. and Finnigan, T.J. (2009) 'Mrs Mop, mechanic and /or miracle worker: metaphors of study support', Journal of Learning Development in Higher Education, Issue 1, February, pp. 1-14.

Burk, D. and Bender, M.A. (2005) 'Use and perceived effectiveness of student support services in a first year dental student population', Journal of Dental Education, 69(10), pp. 1148-1160.

Hall, J. and Peat, J. (2012) 'Using student conversations about learning and teaching to surface troublesome knowledge about the HE classroom', Educational Developments, 13(3), pp. 15-17.

Hill, P., Tinker, A. and Catterall, S. (2010) 'From deficiency to development: the evolution of academic skills provision at one UK university', Journal of Learning Development in Higher Education, Issue 2, February, pp. 1-19. 
Hill, P., Tinker, A., Squires, P. and Kannara, V. (2011) The integration of learning development into the student experience. A University of Huddersfield teaching and learning project. July 2011. Available at:

http://www.hud.ac.uk/media/universityofhuddersfield/content/tlinstitute/documents/pr ojects/projects10/Embedding\%20skills\%20Pat\%20Hill\%20final\%20report.doc (Accessed: 3 March 2013).

Laycock, M. (2008) A 'supportive learning community': recommendations for an institutional framework for student support. Internal document. Oxford: Oxford Brookes University.

Malik, S. (2000) 'Students, tutors and relationships: the ingredients of a successful academic support scheme', Medical Education, 34(8), pp. 635-641.

McGahey, P. and Szumko, J. (2006) 'Relationship at the heart of support work', BRAINHE 2006 Conference. De Montford University, Leicester 15 September.

Mortiboys, A. (2002) The emotionally intelligent lecturer. Birmingham: SEDA.

Mottarella, K.E., Fitzsche, B.A. and Cerabino, K.C. (2004) 'What do students want in advising? A policy capturing study', NACADA Journal, 24(1 \& 2), Spring and Fall, pp. 48-61.

Oxford Brookes University (2010) Strategy for Enhancing the Student Experience. Oxford Brookes University. Oxford. Available at http://www.brookes.ac.uk/services/ocsld/sese/ (accessed 20 March 2013)

Patton, M.Q. (2008) Utilization-focused evaluation. $4^{\text {th }}$ edn. Thousand Oaks, CA: Sage.

Patton, M.Q. (2011) Developmental evaluation, applying complexity concepts to enhance innovation and use. New York: Guildford Press.

Stephen, D., O'Connell, P. and Hall, M. (2008) 'Going the extra mile', 'fire-fighting', or laissez-faire? Re-evaluating personal tutoring relationships within mass higher education', Teaching In Higher Education, 13(4), pp. 449-460. 
Thomas, L. (2012) Building student engagement and belonging in higher education at a time of change: final report from the What Works? Student Retention \& Success programme. London: Paul Hamlyn Foundation.

Yorke, M. (2004) 'Retention, persistence and success in on-campus higher education, and their enhancement in open and distance learning', Open Learning, 19(1), pp. 19-32.

Yorke, M. and Thomas, L. (2003) 'Improving student retention from lower socio-economic groups', Journal of Higher Education Policy and Management, 25(1), pp. 63-74.

\section{Author details}

Dr. Rhona Sharpe is Head of the Oxford Centre for Staff and Learning Development at Oxford Brookes University. She is the editor of the Brookes eJournal of Learning and Teaching, and Chair of ELESIG (Evaluation of Learners' Experiences of elearning Special Interest Group). She is a Senior Fellow of the Staff and Educational Development Association, a Fellow of the Higher Education Academy and a National Teaching Fellow.

Dr. Frances Deepwell is an Educational Developer in the Oxford Centre for Staff and Learning Development at Oxford Brookes University. Her main interests lie in the areas of programme and project evaluation; continuing professional development for learning and teaching beyond initial training; institutional innovation and change. She is Senior Fellow of the Higher Education Academy and Senior Fellow of the Staff and Educational Development Association.

Patsy Clarke spent four years as an Educational Developer in the Oxford Centre for Staff and Learning Development at Oxford Brookes University, where she supported a number of research projects including an Appreciative Inquiry for the JISC-funded Users and Innovation Research Programme. Since her retirement, Patsy freelances as a researcher and NVIVO software trainer. 